\title{
A DESATENÇÃO COMO UM ECO DA PAIXÃO PELO REAL'
}

Luciana Azevedo Rodrigues*

Márcio Norberto Farias**

RESUMO: Este artigo discute como a virtualização do real, promovida pela atual indústria cultural, vem conduzindo ao enfraquecimento da capacidade das pessoas de prestarem atenção na leitura de textos. O trabalho argumenta que a paixão pelo real produz, como um de seus resíduos, a dificuldade das pessoas em se deterem perante algo, ao mesmo tempo em que torna a desatenção um índice da angústia do particular, que não encontra formas de expressão. A primeira parte aborda as reflexões adornianas sobre o pseudorrealismo; a segunda retoma as explicações freudianas sobre o sistema perceptivo-consciente e a abordagem de Zuin acerca delas; a terceira parte discute as análises de Zizek sobre o efeito espetacular do Real; e a quarta parte, além da abordagem de Türcke sobre o processo da leitura, reflete os ecos da universalização da irrealidade sobre a desatenção na leitura de textos.

Palavras-chave: Desatenção. Indústria Cultural. Virtualização. Real.

\section{INATTENTION AS AN ECHO OF ONE'S PASSION FOR 'THE REAL'}

ABSTRACT: This article discusses how reality has become (intentionally) "virtualized", or rather turned into something virtual, by our contemporary Culture Industry, and how this, in turn, has been leading to a weakening of people's reading attention-spans. The work argues that in their passion for something real a residue is left (or a side-effect is felt), of a reduced ability to give anything one's full attention, while, at the same time, this inattention becomes a measure of a person's anguish as he/she fails to find a way of expression (a way to express him or herself). The first part is about Adornian's reflections on pseudo-realism; the second, summarizes Freudian explanations concerning the perception-consciousness system, and Zuin's approach to them; the third part discusses Zizek's analyses of the outstanding effect of "The Real"; the fourth, as well as exploring Türcke's approach towards the process of reading, reflects on the universal/ubiquitous echoes of unreality (or pseudo-reality) where inattention to the reading of texts, is concerned.

Keywords: Inattention. Culture Industry. Virtual. Real.

\footnotetext{
* Doutora em Educação pela Universidade Federal de São Carlos (UFSCar) e Professora Adjunta do Departamento de Educação da Universidade Federal de Lavras (UFLA). E-mail: luazevedo@ded.ufla.br

* * Doutor em Sociologia pela Universidade Universidade Estadual Paulista "Júlio de Mesquita Filho" (UNESP) e Professor Adjunto do Departamento de Educação Física da Universidade Federal de Lavras (UFLA). E-mail: marxio@def.ufla.br
} 


\section{Considerações iniciais}

Desde o final do século XX até hoje, finalizada a primeira década do século XXI, o tema da desatenção vem sendo discutido no interior de diferentes áreas do conhecimento, sendo a neurofisiologia e a neuropsiquiatria as áreas que mais o abordam. Dentro desses campos teóricos, a falta de atenção vem sendo denominada de Transtorno do Déficit de Atenção - TDA - e compreendida como uma doença que, entre outras, encontra suas causas nos organismos específicos de cada sujeito. Além desse horizonte de estudos, a desatenção também vem sendo analisada por estudiosos do campo educacional, que discutem como a capacidade atentiva depende da perspectiva pedagógica adotada pelo docente no interior da sala de aula, podendo ser mais ou menos mobilizada. Assim, enquanto, nas perspectivas neuropsiquiátrica e neurológica do TDA, a desatenção acaba recaindo sobre a constituição biofísica do próprio aluno compreendida em si mesma, nas abordagens pedagógicas, tende a ser explicada como um reflexo da falta de conhecimentos metodológicos e da desconsideração docente pelas significações realizadas pelos estudantes no processo de ensino-aprendizagem.

Sem negar a relevância e a contribuição dessas duas perspectivas de estudo e a complexidade do problema da desatenção, este trabalho, de caráter teórico e ensaístico, visa a afirmar a necessidade de investigações sobre os impactos do desenvolvimento tecnológico dos aspectos realistas dos produtos da indústria cultural contemporânea para a desatenção, de modo que ela não seja reduzida à expressão de "organismos deficientes" ou de "professores despreparados", abordados em si, isoladamente. Com o intuito de compreender a desatenção como expressão de relações determinadas socialmente, este trabalho discorre sobre a intensificação do consumo de choques imagéticos alcançada com o aperfeiçoamento tecnológico dos produtos do que Adorno e Horkheimer (1985) chamaram de "indústria cultural". Um sistema que tem sido indispensável para a continuidade do sistema econômico capitalista, mas que também vem produzindo, como um dos seus efeitos inevitáveis, o desgaste dos sentidos humanos.

Ao retomar as ideias de Adorno (1995) sobre o pseudorrealismo, de Freud (1996) e Benjamin (1989) sobre o choque, de Zizek (2003) sobre a virtualização da realidade e do real, e de Türcke (2008) acerca dos hiper- 
textos, o trabalho argumenta que a paixão pelo Real produz como um de seus resíduos a dificuldade das pessoas em se deter perante algo, ao mesmo tempo que torna a desatenção um índice da angústia do particular que não encontra formas de expressão. Pois, no contexto social mediado pelos produtos da indústria cultural, em que o fascínio se volta para um real virtualizado, isento de seu núcleo duro e resistente, quanto mais a atenção é requerida e exercitada, menos ela se desenvolve.

\section{Modelos ideais, reprodução da realidade e repetição da sensação}

A oposição de Adorno (1995) à proposta, feita por um pastor protestante, de apresentar uma família feliz na televisão para orientar as pessoas a adotarem uma vida familiar positiva elucida sua preocupação em contrapor-se ao processo de harmonização do mundo e aos modelos ideais promovidos pelos programas televisivos e por todo o sistema da indústria cultural. Hoje, esse contrabando ideológico, obtido com a apresentação permanente desses modelos na e pela televisão, torna-se gradativamente mais poderoso com o aperfeiçoamento do aparato de reprodução tecnológica e o consequente aprimoramento do rigor com que reproduz a realidade. Com tal refinamento, o caráter venal dos modelos idealizados, presente nos produtos da indústria cultural, torna-se ainda mais percebido como espontaneidade e isenção de interesses, fortalecendo uma percepção falsa da vida.

O brilho de poder, emprestado ao indivíduo mediante a oferta de modelos ideais, relaciona-se com a vida apenas como um momento que realiza o valor de troca; daí Horkheimer e Adorno (1985), diante da afirmativa dos defensores da indústria cultural de que ela se pauta e atende às necessidades de seus consumidores, dizerem que "De fato, o que o explica [o consumo dos produtos da indústria cultural] é o círculo da manipulação e da necessidade retroativa, no qual a unidade do sistema se torna cada vez mais coesa" (ADORNO; HORKHEIMER, 1985, p. 114).

Nesse círculo, porém, a necessidade dos consumidores não é compreendida pelos frankfurtianos como algo dado; corresponde, pelo contrário, a algo socialmente desenvolvido num sistema econômico historicamente determinado e que se expressa em cada consumidor, necessitado de repetir em si a sensação de dominação e de utilização de algo. 
Sensação que, além de ofuscar o olhar diante da dilapidação das relações sociais pela expansão do princípio da troca, torna o sujeito cada vez mais insensível ao próprio sofrimento como fruto de relações de produção que o reduzem a mero instrumento de obtenção de mais-valia.

A percepção do prolongamento da tela na vida e vice-versa, promovida com o aperfeiçoamento técnico e tecnológico dos produtos da indústria cultural, torna-se fundamental para que os danos da proliferação de relações eivadas pelo princípio da troca não sejam reconhecidos e a ideia de que a vivência de relações humanas imediatas depende exclusivamente dos esforços de cada pessoa seja fortalecida.

Em um de seus textos educacionais, Adorno chama a realidade apresentada na televisão de pseudorrealista, justamente “(...) porque até mesmo o último detalhe da televisão é perfeito (...)" (1995, p. 85). Complementa dizendo:

Eles são tão perfeitos, tão realistas, que o contrabando ideológico se realiza sem ser percebido, de modo que as pessoas absorvem a harmonização oferecida sem ao menos se dar conta do que lhes acontece. Talvez até mesmo acreditem estar se comportando de um modo realista (ADORNO, 1995, p. 86).

O hiper-realismo das imagens, que hoje vivenciamos, em vez de simplesmente negar o não-harmonizável, explora-o, oferecendo-o como mais um produto de consumo. A sensação de harmonia perante a utilização de tudo, inclusive do não-harmonizável, produzida com o hiper-realismo das imagens, conduz à convicção de que o seu consumo significa valorizar e adotar um comportamento realista. Ao oferecer a realização humana no atual modo de organização social como algo que depende exclusivamente do interesse de cada pessoa, a perfeição do mundo midiatizado constitui-se como forma de repressão de todo vestígio de "imperfeição". Enredando-se aos modelos idealizados e propagandeados nas imagens produzidas tecnologicamente, a própria pessoa passa a colaborar com o processo que exclui o que lhe é particular, ajustando-se à ordem social que só admite a existência como meio para obtenção de lucro.

Devido a esse caráter ideologizante da televisão, mobilizador de uma consciência falsa, o filósofo frankfurtiano sugere a utilização de um realismo artístico. Diz ele: “[...] a possibilidade de despertar a consciência da realidade vincula-se em grande parte à desistência em reproduqiir mais uma vez a realidade superficial cotidiana visivel em que vivemos" (ADORNO, 1995, p. 
86, grifo nosso). Nesses termos, sugere que quanto mais a realidade superficial cotidiana visível é reproduzida nas telas de computadores, televisão e celulares, maior é a dificuldade de despertar a consciência para a historicidade que constitui tanto a realidade quanto ela própria.

A capacidade de promover a percepção de que o mundo da tela se prolonga no da rua faz com que os produtos da indústria cultural atinjam diretamente o corpo, a pulsão; impulsionando-o a repetir o já existente, a experimentar o que é próprio do modo de produção de mercadorias - o excesso. Um excesso vivido em cada volta à posição de consumidor, onde a atuação como tal o faz esquecer, impedindo-o de perceber a própria historicidade do processo que exige cada vez mais de si, de tudo e de todos. Como observa Ramos (2008, p. 6), "Aliada à realidade, o que a ideologia contemporânea oculta não é mais as suas contradições, mas a sua historicidade". Insufladas pelo poder dos modelos idealizados, as pessoas experimentam seus excessos e submetem-se, cada vez mais, aos choques imagéticos.

As imagens extraídas das ruas, e não mais produzidas em estúdios, de pessoas comuns nos seus espaços cotidianos, finalizadas em ilhas de edição ou simplesmente veiculadas pelos diferentes aportes tecnológicos, não significam, assim, a superação dos modelos ideais, mas o refinamento dos mecanismos que os produzem, que elogiam o real e as posturas subjetivas orgulhosamente chamadas de realistas. Nesse processo, intensifica-se a dificuldade em perceber a ilusão de que tudo pode ser resolvido exclusivamente pela força individual, enquanto a conciliação com a realidade é produzida não a partir da própria realidade, mas pela conservação artificial de modelos ideais percebidos cada vez mais como reais e orientadores de condutas. Desse modo, as pessoas absorvem a vida artificialmente definida, nos seus mínimos detalhes, como moldes para organizar suas próprias vidas; e a ideologização da vida, promovida na televisão, neste início do século XXI, assume nuanças um pouco diferenciadas do formato analisado por Adorno, em meados do século XX.

Os quadros televisivos do século XXI não trazem apenas uma vida familiar positiva. Apresentam o cotidiano concreto de uma, submetendo-a ao olhar de conselheiros e especialistas, que identificam os erros cometidos pelas pessoas e prescrevem o que e como se deve fazer para chegar a uma vida familiar bem-sucedida, seja na relação com os cachorros, seja com a mãe, com o filho, com o pai, com o marido, com a espo- 
sa, com a enteada, com a madrasta, com o padrasto, etc., numa espécie de reality show.

Pode-se dizer que não há mais simplesmente uma encenação daquela harmonização, com a presença de atores e atrizes profissionais, mas a filmagem de famílias reais, a observação de suas condutas por profissionais de diferentes áreas do conhecimento, que definem o certo e o errado a partir dos óculos da produção, nos sets de filmagem. Desse modo, o programa televisivo se apresenta como realista e capaz de intervir eficientemente na realidade, aperfeiçoando-se como instrumento que reforça a ideologização da vida. Nesse processo de atualização de seu compromisso com o status quo, o programa televisivo prolonga a encenação de atores e atrizes profissionais na pele das pessoas em seus cotidianos, afastando-as ainda mais da compreensão de si mesmas como expressões das contradições do contexto econômico, histórico, político e cultural mais amplo.

Se, na encenação da vida, harmonizada com a ajuda de atores e atrizes profissionais, havia maior possibilidade de o espectador discernir entre uma produção artificial da vida saudável e as condições concretas de esvaziamento das relações humanas na sociedade voltada para o lucro, a “intervenção televisiva”, que conserva o mundo como está e, ao mesmo tempo, se apresenta como transformadora dos próprios espectadores, fortalece ainda mais a ideia de que os problemas e as contradições sociais podem e devem ser tratados e solucionados nos planos subjetivo e intersubjetivo.

Como a origem do problema é identificada na pessoa, compreendida em si mesma como algo dado e alterável por sua vontade e reconhecimento, a solução se torna ainda mais baseada no seu esforço e na sua dedicação para mudar. Os programas que oferecem modelos ideais, na pele de astros e estrelas, e que não deixaram de existir passam então a dividir espaço com programas que permitem a encenação de tais modelos pelos próprios sujeitos, em suas casas, camas e mesas, dificultando ainda mais o processo de desenvolvimento de uma consciência da realidade, referido por Adorno. Quanto mais a vida é rigorosamente reproduzida nas telas, mais difícil se torna o exercício de sua representação, e mais as suas imagens se dirigem ao corpo, impactando-o. A exposição do corpo e dos sentidos humanos a imagens cada vez mais chocantes, proporcionada pelos produtos da indústria cultural, exige que a intensidade 
das descargas de choques oferecidos seja cada vez maior, pois a continuidade do consumo de seus produtos depende dessa intensificação. Esta, por sua vez, não cessa de reproduzir a insensibilização da capacidade reflexiva e perceptiva das pessoas.

\section{Choques como forma de proteção contra a angústia}

Se, de um lado, os modelos idealizados dos produtos da indústria cultural invadem a realidade, promovendo a idealização do indivíduo como sendo aquele que pode e deve mudar o rumo de sua vida, de outro lado, os choques vivenciados com seu consumo não cessam e não deixam de ser buscados como forma de as pessoas lidarem com a própria angústia.

Para entender a ininterrupta busca das pessoas pela excitação dos sentidos, provocada pelos produtos da indústria cultural, Zuin (2008) propõe a retomada dos estudos freudianos sobre a ruptura do escudo protetor que permite ao sistema perceptivo humano se defender dos inúmeros estímulos e, assim, conseguir recebê-los. Diz Zuin:

Freud enfatizou a relevância do susto na investigação dos danos psíquicos. $\mathrm{O}$ susto seria causado pela falta de preparação para a angústia: uma vez que o organismo não se prepararia com antecedência para registrar o choque a ser recebido, as defesas do aparelho psíquico estariam relaxadas (...) Em virtude da baixa catexia (ou seja, das pequenas quantidades de energias psíquicas ligadas às representações mentais do indivíduo), o aparelho psíquico não teria forças suficientes para vincular, ou seja, catexizar as quantidades afluentes de excitação em representações mentais que proporcionariam certa organização mental. (2008, p. 56)

Freud (1996), ao falar sobre o trauma, também reconhece que a brincadeira infantil e os sonhos dos neuróticos traumáticos funcionam como formas de ativar o processo de arregimentação de energias psíquicas posteriormente à vivência do trauma, de modo a tornar possível a experiência de preparação para a angústia e de vinculação da excitação vivida com representações capazes de proporcionar alguma satisfação. Benjamin (1989) parece reconhecer um processo semelhante na produção escrita dos poemas de Baudelaire, especialmente na sua esgrima com as 
palavras, referida como uma luta árdua do poeta, que repetia até a exaustão seu trabalho de elaboração dos choques vividos em meio à multidão, tão fundamentais para a singularidade de sua poesia. Nesses termos, Benjamin sugere que a defesa dos choques apenas pode ser experimentada posteriormente, mediante a sua rememoração e escrita, numa espécie de repetição que permite a reunião de energia psíquica suficiente para vincular as excitações vividas a representações.

Quando isso é dificultado pela vivência contínua de repetições, organizadas por mecanismos externos ao sujeito, o processo que levava à representação das excitações internas encontra poucas ou nenhuma chance para ocorrer. Quando essa repetição que proporciona a sujeição de excitações se torna inviável, as excitações internas não sujeitadas com a representação assumem o comando do Eu e o levam a se relacionar cegamente com os objetos à sua volta. Governado por tais excitações internas não representadas, o Eu perde a capacidade de distinguir e de se diferenciar do mundo, de seu entorno, relacionando-se com ele apenas como reflexo de si mesmo.

Conforme Zuin:

Se a preparação para a angústia é uma das últimas linhas de defesa do aparelho psíquico contra o afluxo de estímulos externos, e se a ausência dessa preparação e a falta de hipercatexia dos sistemas receptivos são decisivos para a ocorrência do choque e para a formação do trauma, parece haver uma contradição com a assertiva anterior de que as pessoas, na sociedade da atual indústria cultural, procuram compulsivamente os choques - os quais não por acaso, se tornam cada vez mais intensos (2008, p. 56, grifo nosso).

Quanto mais as pessoas se submetem aos choques, mais seus sistemas perceptivos-conscientes permanecem hipercatexizados, e menos dispõem de energias psíquicas para vincular as excitações vividas a representações mentais. O fortalecimento de seus escudos protetores de choques, além de dificultar a percepção do que não é vivido na forma de choques, captura as energias e os esforços necessários para a elaboração das excitações externas que se internalizaram, impedindo que elas sejam experimentadas com o relaxamento do sistema consciente-perceptivo, tal como Freud observou na brincadeira infantil e nos sonhos dos neuróticos traumáticos, e Benjamin destacou na escrita/esgrima de Baudelaire. A frequência cada vez menos interrompida e a intensidade dos choques for- 
mam condições objetivas que desfavorecem e até obstaculizam a experiência de relaxamento referida, necessária ao processo de repetição e de desenvolvimento da representação.

Em Freud, é possível observar ainda que os sustos derivam da insuficiente preparação para a angústia e precisam ser revividos para que seja arregimentada uma quantidade de energia psíquica capaz de vincular a excitação tornada interna às representações psíquicas. Esse reviver, porém, encontra dificuldades para se realizar devido à submissão do sistema consciente a mais excitações externas promovidas pelos produtos da indústria cultural. Com isso, a excitação tornada interna, impedida de assumir a forma de representação, sem poder experimentar o prazer oriundo desse processo, só pode ser vivida como choque atualizado externamente pelos produtos da indústria da cultura, fortalecendo-se como um modo de evitar toda a experiência efetiva com o que é externo e diferente.

Zuin (2008) destaca que existe uma aparente contradição no desejo das pessoas pela excitação, pois, em vez de ser contraditório, ele se harmoniza com a sociedade de consumo cada vez mais excitada. A permanente subordinação dos sujeitos aos choques provocados pela multidão de pessoas, de imagens, de informações, de sensações, ao impossibilitar que a angústia provocada seja revivida e elaborada, impede, por isso mesmo, que ela se converta em algo que atrapalhe o processo de adaptação do sujeito à totalidade social.

Após evidenciar que a sensação de angústia, para Freud, é engendrada quando alguma excitação psíquica ou física não encontra representação mental para se vincular, Zuin (2008) afirma que tal sensação, por não alcançar o prazer da elaboração psíquica com a sua fixação no encontro com uma representação mental, passa a ser gozada masoquistamente e, em seguida, é descarregada sadicamente.

Para Zuin (2008), a frustração de não poder fruir do prazer oriundo da fixação do que foi sentido, da impossibilidade de convertê-lo em representação, de fruir algum controle em si e sobre si, incita a busca pela compensação no gozo de um prazer sadomasoquista maior e, assim, sucessivamente, numa repetição que o logra, aproximando o indivíduo de um estado de não-vida, no sentido destacado por Freud, numa repetição da pulsão de morte.

Em consequência disso, Zuin (2008) conclui que os produtos da atual indústria cultural reforçam o argumento freudiano de que o princí- 
pio do prazer se coloca a serviço da pulsão de morte. Em suas palavras: “(...) a necessidade de sentir a máxima excitação (...) encontra correspondência na descarga não menos potente de energia psíquica” (2008, p. 57). Assim, a excitação provocada pelo turbilhão de imagens proporcionado pelos produtos da indústria cultural atualiza, ao mesmo tempo, o susto e a sensação de uma descarga brutal de energias, que não puderam se fixar em representações mentais e proporcionar um prazer oriundo dessa fixação e controle.

A procura por choques cada vez mais intensos e violentos, ao mesmo tempo que obstrui a repetição para a elaboração da angústia e a incorporação da excitação experimentada, impõe doses mais fortes de excitação- imagens ao sistema perceptivo, as quais recordam o que Zizek (2003) chamou de obscena brutalidade do poder.

Dessa maneira, o susto como estigma do despreparo diante de algo, de uma insuficiência, é submetido a sua permanente atualizaçãoatuação para não ser reconhecido; e, por meio de mais choques, a ele é negada a possibilidade de elaboração, de admissão de uma existência simbólica. Afastado de toda forma de representação, o susto é, permanentemente, repetido mediante a subordinação aos choques imagéticos proporcionados pelos produtos da indústria cultural, numa espécie de acting-out do susto. Zizek (2003) nos incita a pensar nisso quando fala da entrada do efeito espetacular do Real na realidade das pessoas.

\section{A importância do efeito espetacular do real como forma de fugir da realidade real e do próprio real}

Zizek (2003), filósofo esloveno que vem discutindo, na sociedade contemporânea, o que ele chama de "paixão pelo real", chega a afirmar que o comportamento de pessoas que cortam seu próprio corpo ou impigem dor à própria pele não pode ser compreendido como um fenômeno sustentado numa ordem simbólica, mas, pelo contrário, está baseado na realidade do corpo, na sua concretude, por meio da qual se torna possível às pessoas "lidar" com a angústia de se sentirem inexistentes.

A presença crescente, no mercado, de produtos esvaziados de sua substância, tais como o café sem cafeína, a cerveja sem o álcool, o sexo sem sexo e o Outro sem Alteridade, citados pelo próprio Zizek 
(2003), levam-no a falar da existência de uma realidade sem realidade, produzida com a realidade virtual. Com ela, o filósofo considera que as pessoas passaram a acessar uma realidade esvaziada do núcleo duro e resistente do Real, e marcada pela invasão dos efeitos espetaculares do Real na realidade. Nesse contexto, enquanto a própria possibilidade de relação com o que escapa do controle é destruída, o já temido e desejado é realizado nas telas, de modo que as pessoas possam, a partir delas, tocar e perceber a própria realidade. A ideia é exemplificada e discutida por Zizek a partir do ataque terrorista às torres gêmeas do World Trade Center WTC, no dia 11 de setembro de 2001.

O enquadramento das imagens da realidade, tal como vinha e vem sendo feito na produção de imagens cinematográficas, e a prévia constituição de um público habituado a ver os ataques terroristas apresentados por Hollywood fizeram com que o Real se tornasse um surpreendente efeito especial. Diz o filósofo: “(...) para nós corrompidos por Hollywood, as imagens da queda das torres só poderiam ser uma reprodução das cenas mais emocionantes das grandes produções sobre catástrofes" (ZIZEK, 2003, p. 30).

Zizek (2003) argumenta ainda que o choque das imagens hollywoodianas de catástrofe permitiu que as pessoas estivessem preparadas para a impensada transposição das fantasias para a realidade, pois, em suas palavras, "Não se tratou apenas do fato de a mídia nos bombardear constantemente com a ameaça terrorista; essa ameaça tinha uma representação libidinal (...) os Estados Unidos haviam transformado em realidade as suas fantasias" (ZIZEK, 2003, p. 30).

Propondo a inversão da leitura mais comum de que as explosões do WTC significaram a invasão do Real e o estilhaçamento da nossa esfera ilusória, Zizek afirma que, antes dessas explosões, os americanos viviam a realidade assistindo aos horrores dos países do terceiro mundo. Nas palavras do filósofo, "Não foi a realidade que invadiu a nossa imagem: foi a imagem que invadiu e destruiu a nossa realidade (ou seja, as coordenadas simbólicas que determinam o que sentimos como realidade)" (2003, p. 31).

Ao nosso ver, a leitura de Zizek (2003) encontra forte relação com a compreensão dos frankfurtianos, expressa no famoso texto "Indústria Cultural: esclarecimento como mistificação das massas", quando afirmaram que o primeiro serviço prestado pela indústria cultural aos 
seus clientes é a expropriação do Esquematismo. Conforme Adorno e Horkheimer:

A função que o esquematismo Kantiano ainda atribuía ao sujeito, a saber, referir de antemão a multiplicidade sensível aos conceitos fundamentais, é tomada ao sujeito pela indústria. (...) $\mathrm{Na}$ alma devia atuar um mecanismo secreto destinado a preparar os dados imediatos de modo a se ajustarem ao sistema da razão pura. (...) Para o consumidor, não há nada mais a classificar que não tenha sido antecipado no esquematismo da produção (1985, p. 117).

A preparação dos dados imediatos, antes realizada em estúdios de filmagens, foi condição para o desenvolvimento da percepção da realidade retratada por Zizek (2003). Pode-se dizer que a produção não corresponde à apresentação recortada do real, mas de imagens que organizaram a percepção dos acontecimentos reais, veiculadas a todo o momento pelos produtos da indústria cultural, capazes de, ao mesmo tempo, oferecer o real e manter os sujeitos dele protegidos. Nesse sentido, o esquematismo da produção encontra sua máxima realização na apresentação do Real, confirmando a consideração de Adorno e Horkheimer de que a reprodução rigorosa do mundo da percepção cotidiana tornou-se a norma da produção cinematográfica. Nas palavras dos pensadores,

Quanto maior a perfeição com que suas técnicas duplicam os objetos empíricos, mais fácil se torna hoje obter a ilusão de que o mundo exterior é o prolongamento sem ruptura do mundo que se descobre no filme. (ADORNO; HORKHEIMER, 1985 , p. 118, grifo nosso)

A ilusão de que o mundo descoberto no filme é o mesmo do mundo exterior, referida pelos frankfurtianos, é fortalecida com o progresso da capacidade tecnológica de reprodução/difusão da realidade cotidiana; e seu ápice pode ser visto na abordagem de Zizek, quando este argumenta que o ataque terrorista, no dia 11 de setembro de 2001, proporcionou o efeito especial em que a realidade real foi invadida pela imagem espetacular do Real. Com a invasão do efeito espetacular do Real na realidade, as pessoas passam a perceber a realidade real como virtual e sentem aumentar a angústia de se sentir inexistentes.

Ao se referir ao que Lacan chama de "atravessar a fantasia", Zizek destaca que a imersão na realidade depende da imersão na fantasia. 
Explica, ao citar Boothby, que a fantasia é, ao mesmo tempo, pacificadora e destruidora, e exemplifica a referida travessia comentando a atitude irônica de uma banda de rock frente à situação de guerra e fome da população de Sarajevo. Conforme o filósofo:

Assim se demonstrou que o caminho da verdadeira solidariedade passa pela confrontação direta com as obscenas fantasias racistas que circulavam no espaço simbólico da Bósnia pela identificação sarcástica com elas, e não pela negação dessas obscenidades porque elas não representam as pessoas tal como "realmente são" (ZIZEK, 2003, p. 33).

Para o filósofo, a simples negação dessas obscenidades não permite a confrontação com o Real, não contribui para o desenvolvimento de sua expressão ficcional na realidade, pois a dialética do real não se expressa apenas na necessidade das pessoas de buscar um terreno firme, em alguma realidade real, para lidar com o processo de virtualização da vida cotidiana, mas na impossibilidade do Real, devido ao seu caráter excessivo e traumático, de integrar o que é sentido como realidade e, por isso mesmo, só pode ser sentido como um pesadelo fantástico. De acordo com Zizek, "A impressionante imagem de destruição do WTC foi exatamente isso: uma imagem, um semblante, um 'efeito' que, ao mesmo tempo, ofereceu a 'coisa em si"' (2003, p. 34). Nesse sentido, em vez de ser atravessada, a fantasia encontrou uma imagem que a reflete objetivamente, graças ao aparato de reprodução tecnológica, fundamental no que se refere a emprestar uma imagem, um corpo, para o que se permitia sentir tão somente como pesadelo.

Zizek alerta que "[...] é preciso ter a capacidade de discernir naquilo que percebemos como ficção, o núcleo duro do Real, que só temos condições de suportar se o transformarmos em ficção" (2003, p. 34). Ao indicar que a realidade não mais vem sendo percebida como o verdadeiro contrário do Real, Zizek questiona se o corte que as pessoas fazem em seus corpos não expressa uma fuga não só da sensação de irrealidade oriunda da vida virtualizada, mas do próprio Real, que, por não ser transformado em ficção, tende a eclodir como alucinações descontroladas ou então acessos “irracionais” de fúria destrutiva. Diz ele:

Não se trata apenas de Hollywood representar um semblante da vida real esvaziado do peso e da inércia da materialidade- na sociedade consumista do 
capitalismo recente, 'a vida social real' adquire de certa forma as características de uma farsa representada em que nossos vizinhos se comportam "na vida real" como atores num palco (ZIZEK, 2003, p. 28, grifo nosso).

Assim, enquanto a realidade é purificada dos elementos que resistem à sua manipulação ou daquilo que a torna hostil ao primeiro contato, as pessoas agem como se estivessem encenando a si mesmas. Tal encenação indica quão atravessadas elas estão pelos efeitos espetaculares do real, invadido pelas imagens artificiais dos produtos da indústria cultural.

De acordo com o filósofo esloveno, como o caráter excessivo e traumático do Real impede sua integração na nossa realidade e só pode ser sentido como um pesadelo fantástico, o confronto com ele, seja como pesadelo, seja transfigurando-o em ficção na realidade, é evitado mediante o consumo das imagens espetaculares do real.

\section{Desatenção:}

\section{testemunho dos choques e da virtualização do real}

Dizer que a vida foi virtualizada implica, pelo que vimos até este momento, apontar que as imagens reproduzidas com os produtos da indústria cultural se tornaram referências para percepção do real, de tal modo que ver as explosões de WTC implica rever as explosões artificialmente produzidas por Hollywood. Tal penetração do artificial na realidade, entretanto, permitiu que o Real, com seu caráter excessivo e traumático, encontrasse na realidade imagens que o refletissem, deixando de ser confrontado e suportado como algo que depende de um aporte ficcional.

Quando Türcke (2004), filósofo alemão contemporâneo, argumenta que o telespectador, ao acompanhar cenas de violência ao vivo, desenvolve uma lascívia derivada da sua condição de estar perto e distante de situações perigosas, identificamos nela o que Zizek (2003) chama de realidade sem realidade, capaz de permitir às pessoas acompanharem o perigo e a morte sem serem afetadas por eles. Tal lascívia, segundo Türcke (2004), gera um senso de irresponsabilidade nas pessoas e as desacostuma de avaliar situações reais de perigo. Exemplifica isso comentando um assassinato ocorrido em Frankfurt am Main, em que a multidão se aproximou do lugar e do próprio assassino, sem medir a possibilidade de também ser alvejada. Diz ele: 
quando o poder de fascinação da sensação audiovisual desperta a força de integração da sociedade, cresce a necessidade de se lançar, de forma imediata, à vida real e seus perigos, como se se estivesse sob o efeito de um feitiço audiovisual. $\mathrm{O}$ indivíduo que pode desejar a derrocada da vida real é aquele que se sente enganado na sua própria vida. Ele não tem o controle de sua vida que é devidamente calculada como se fosse uma mercadoria, ao mesmo tempo que se transforma num telespectador que se protege da vida real por meio de uma tela (TÜRCKE, 2004, p. 70, grifo nosso).

Nesse contexto, em que o se lançar na vida real é delineado pela sensação audiovisual, a dificuldade de dedicar atenção e de permanecer envolvido com a leitura de um texto pode ser pensado não apenas como um déficit, diagnosticado em algumas pessoas e explicado a-historicamente, ou, ainda, como um problema originado dentro da sala de aula, pela forma como os professores lidam com as contribuições de seus alunos, mas algo que se reproduz numa cultura sustentada na virtualização do real, responsável por fornecer às pessoas a sensação de escapar não só da sensação de irrealidade, provocada pela virtualização da vida, mas do próprio Real, que sem ser transfuncionalizado num modo ficcional da realidade, pode atormentar com "alucinações" ou "acessos de fúria inexplicáveis".

Quando as pessoas passam horas completamente absorvidas pelas imagens nas telas da televisão, do cinema e do computador, além de vivenciarem a identificação com os modelos idealizados oferecidos pelos produtos da indústria cultural e atualizarem o susto e a angústia com imagens cada vez mais chocantes, tornam-se cada vez menos capazes de perceber o que não possui a forma do choque, o que oferece resistências à sua manipulação por não ter sido previamente percebido como espetáculo. Ao expressarem descontentamento e grandes dificuldades de permanecerem atentas, por algum tempo, diante da leitura de um texto, as pessoas também evidenciam a força dos processos que reduzem a atenção a mero aparador de choques e refletem o desespero diante da possibilidade de se deparar com a própria angústia, insuportável quando não encontram meios para tornarem-na representável, na realidade virtualizada.

Sobretudo ao desenvolverem uma irresponsabilidade diante de situações reais de perigo, as pessoas vivenciam uma sensação de onipotência cada vez mais intensa, que as torna alérgicas a todo e qualquer signo de insuficiência. E é justamente esse signo, conforme Türcke, que um texto carrega. Em suas palavras: 
Todo texto situa-se aquém da experiência que ele comunica, mas é apenas por meio do texto e das estruturas de linguagem que a experiência consegue superar sua limitação monádica. (...) E tais estruturas não podem existir sem a seqüência sujeito, predicado, objeto e sem a hierarquia de conceitos genéricos e subordinados. Elas são tão indispensáveis e insuficientes como a ordem alfabética nos dicionários. Sua insuficiência incomoda, mas ela faz com que o texto aponte para além de si mesmo. Sem provocar o leitor para a elaboração de seu próprio construto representacional, o qual é tampouco trivialmente idêntico com a seqüência de palavras impressas, quanto com construto do autor, nenhum texto poderia ser palpitante (2008, p. 33, grifo nosso).

Assim, a insuficiência da estrutura sequencial e hierárquica do texto, que permite apontar para "além de si mesmo" e apresenta as resistências de que a experiência precisa para se representar como algo diferente daquelas sequências, esbarra na virtualização do real, que produz a lascívia e a sensação de onipotência que renega todo tipo de relação com o que resiste à manipulação. Nesse contexto, a resistência que o texto coloca para que o leitor desenvolva o que ainda não foi pensado ou ainda não existe é percebida como algo cada vez mais hostil. A insuficiência inerente ao texto faz lembrar a vivida pelo próprio indivíduo, que não encontra condições para elaborar a angústia e, devido à virtualização da existência e do próprio Real, adere aos produtos da indústria cultural e à confirmação do choque, que não deixa espaço à preparação para a angústia, permitindo apenas uma sensação de descarga de angústia, gozada masoquistamente.

O fortalecimento da sensação de onipotência, derivado da vivência da realidade sem realidade, permite que a atenção seja despertada apenas quando mantida nos trilhos oferecidos pelos produtos da indústria cultural, convertendo-a, por conseguinte, em seu oposto diante do que não carrega a força do impacto. Assim, a desatenção se realiza não como um distúrbio entre outros, mas como a forma de percepção inevitável da sociedade calcada nos choques, no acting out do susto e do exercício do excesso, vivido com as imagens espetaculares do real. 


\section{Referências}

ADORNO, T.; HORKHEIMER, M. Dialética do Esclarecimento: fragmentos filosóficos. Trad. Wolfgang Leo Maar. Rio de Janeiro: Zahar, 1985.

ADORNO, T. W. Televisão e Formação. In: ADORNO, T. W. Educação e Emancipação. Rio de Janeiro: Paz e Terra, 1995.

BENJAMIN, W. Sobre alguns temas em Baudelaire. In: BENJAMIN, W. Obras Escolbidas III. São Paulo: Brasiliense, 1989.

FREUD, S. Além do princípio do prazer. In: FREUD, S. Obras Completas. Volume XVIII. Rio de Janeiro: Imago, 1996.

FREUD, S.; BREUER, J. Recordar, repetir e elaborar. In: FREUD, S; BREUER, J. Obras Completas. Volume II. Rio de Janeiro: Imago, 1996.

RAMOS, Conrado. Consumismo e gozo: uma compreensão de ideologia entre T.W. Adorno e J. Lacan. Psicol. USP. [online], v. 19, n. 2, p. 199-212, jun. 2008. Disponível em: $<$ http://pepsic.bvs-psi.org.br>. Acesso em: 6 abr. 2010.

TÜRCKE, C. Hipertexto. In: DURÃO, F. A.; ZUIN, A.; VAZ, A. F. (Org.) A indústria cultural hoje. São Paulo: Boitempo, 2008.

TÜRCKE, C. Sociedade da sensação: a estetização da luta pela existência. In: ZUIN, A. A. S.; PUCCI, B.; RAMOS-DE-OLIVEIRA, N. (Org.) Ensaios frankfurtianos. São Paulo: Cortez, 2004.

ZIZEK, S. Paixões do real, paixões do semblante. In: ZIZEK, S. Bem vindo ao deserto do real. Trad. Paulo César Castanheira. São Paulo: Boitempo, 2003.

ZUIN, A. A. S. Morte em vídeo: Necrocam e a indústria cultural hoje. In: DURÃO, F. A.;ZUIN, A.; VAZ, A. F. (Org.) A indústria cultural hoje. São Paulo: Boitempo, 2008. 


\section{Nota}

1 Este artigo resulta dos estudos desenvolvidos no Projeto de Pesquisa "Novas tecnologias e desatenção no processo de formação docente", que conta com o apoio financeiro da Fundação de Amparo à Pesquisa do Estado de Minas Gerais - FAPEMIG.

Recebido: $13 / 12 / 2010$

Aprovado: 08/09/2011

Contato:

Universidade Federal de Lavras

Departamento de Educação

Campus Universitário

CEP $37200-000$

Caixa Postal 3037

Lavras, MG

Brasil 